\title{
Adverse Health effects Associated with Shift Work
}

\author{
Murtaza Mustafa $^{1}$, EM.Illzam ${ }^{2}$, AM.Sharifa $^{3}$, RK.Muniandy ${ }^{4}$, K.Fairrul ${ }^{5}$, \\ MK.Nang ${ }^{6}$, MM.Lwin ${ }^{7}$ \\ ${ }^{1,4,5,6}$ Faculty of Medicine and Health Sciences, University Malaysia,Sabah,Kota Kinabalu, Sabah, Malaysia. \\ ${ }^{2}$.Clinic Family Planning Association ,Kota Kinabalu, Sabah,Malaysia \\ ${ }^{3}$ Quality Unit Hospital Queen Elizabeth,Kota Kinabalu,Sabah,Malaysia. \\ ${ }^{7}$ Faculty of Medicine, University Malaysia, Sarawak, Kuching, Sarawak, Malaysia
}

\begin{abstract}
Shift work is the integral part of many occupations. WHO listed shift wok that involves disruption of circadian disruption as a probablecarcinogen? Shift work increases the risk for the development of many health disorders e.g. Sleepdisruption, risk of diabetes,alteration of circadian rhythm,cardiovascular disease, metabolicdisorders, increased risk of breast cancer, stress, reproductive disorders and work place safety and errors. Shiftwork has no adverse effect on mortality. Melatonin may increase sleep length. Modanifil and MRModanifil are useful to improve alertness, reduce sleepiness in shift workers. The license for Modanifil was withdrawn because the benefits did not out way the side effects. Better management of shift work. Frequent breaks and 8-10 hour shifts instead of 12 hour can also minimize fatigue and help to mitigate the negative health effects of shift work.
\end{abstract}

Keywords: Shift work, Circadian rhythm, Cardiovascular disease, Gastrointestinal disease, Occupational stress..

\section{Introduction}

Shift work is an employment practice designed to make use of, or provide service, all 24 hours of the clock each day of the week, also known as 24/7[1].The data from the National Health Interview survey Occupational Health Survey,29 \% of all U.S. workers in 2010 worked as an alternative shift(not a regular day shift[2],15\% of workers worked the night shift regularly[3].Among all occupations, food preparations, and serving occupations had the highest prevalence of working an alternative shift(63\%)[2].Shift work has also been traditional in law enforcement and armed forces military personnel, pilots and others that regularly change time zones while performing shift work experience jet lag and consequently suffer sleep disorders[4].The high prevalence of short sleep duration was reported by night shift workers in the transportation and warehousing $(69.7 \%)$ and health -care and social assistance (52.3\%) industries[5].Shift work increases the risk for the development of many disorders(health disorders) includes: risk of diabetes type 2, women on night shifts have $48 \%$ increased risk of developing breast cancer[,4,6,7].alteration of circadianrhythm, melatonin suppression[8],the WHO listed shift work that involves circadian disruption as a possible carcinogen[9,],Shift work also increases the risk of developing cluster headaches, heart attacks[110],fatigue, stress, sexual dysfunction[12],depression[13], obesity[4,], metabolic disorders, gastrointestinal disorders, musculoskeletal disorders and reproductive disorders [7]. Prevention include management practices, shift system, shift schedule shiftplan, and better management[14,15].The paper reviews the health disorders of shift workers, and preventive measures.

\section{Negative effects}

Shift worker are prone to accidents and injuries. Compared with the day shift, injuries and accidents have been estimated to increase by $15 \%$ on evening shift shifts and $28 \%$ on night shifts .Longer shifts are associated with more injuries and accidents: 10 hour shifts had 13\% more and 12 -hour had 28\% more than 8hour shifts [7].Other studies have showed a link between fatigue and workplace injuries and accidents. Worker with sleep deprivation are far more likely to be injured or involved in an accident [4].One study suggests that for those working a night shift (such as-23-07),it may be advantageous to sleep in the evening(14:00 to 22:00) rather than morning (8:00 to 16:00).The study's evening sleep subjects had 37\% fewer episodes of attentional impairment than the morning sleepers[16].There are four major determinants of cognitive performance and alertness in healthy shift workers. They include: circadian phase, sleep inertia, acute sleep deprivation phase, and chronic sleep deficit [17]

Circadian phase: This phase is relatively fixed in humans attempting to shift it so that an individual is alert during the circadianbathyphase is difficult. Sleep during the day is shorter and less considered than night time sleep [4].Staying awake at night and trying to sleep during the day is not a physiological condition for diurnal creatures such as humans, who are hence forced to adjust their psycho-physiological state by phase 
shift of the daily fluctuation biological functions, which are normally activated during the day and depressed during the night. This phase shift occurs at a speed of about one hour per day and can widely vary according to the duration and extension of night duties along the shift schedule [18].The misalignment of circadian rhythms of body functions is responsible of the so called "jet lag"(or shift lag") syndrome, characterized by feeling of fatigue, sleepiness, insomnia, digestive troubles, irritability, poor mental agility, and reduced performance efficiency; a person recovers in few days depending on the length of phase shift[19].

Sleep inertia: The effects of sleep inertia wear off after 2-4 hours of wakefulness such that most workers who wake up in the morning and go to work suffer some degree of deep sleep inertia at the beginning of their shift. The relative effects of sleep inertia vs other factors are hard to quantify; however the benefits of napping appear to outweigh the cost associated with sleep inertia [17].

Acute sleep deprivation: Acute sleep deprivation occurs during long shifts with no breaks, as well as during night shifts when the worker sleeps in the morning and awake during afternoon, prior to work shift. A night shift worker with poor daytime sleep may be awake for more than 18 hours by the end of the shift. The effects of acute sleep deprivation can be compared to impairment due to alcohol intoxication[4], with 19 hours of wakefulness corresponding to a BAC $0.05 \%$, and 24 hours of wakefulness corresponding to a BAC of $0.10 \%[7]$.Much of acute sleep deprivation can be counted by napping with longer naps giving more benefit than shorter naps[20].Some industries, specifically the Fire Service, have traditionally allowed workers to sleep while on duty, between calls for service. In one study of EMS providers, 24 hours shift were not associated with a higher frequency of negative safety outcomes when compared to shorter shifts[21].

Chronic sleep deficit occurs when a worker sleeps for fewer hours than is necessary over multiple days or weeks. The loss of two hours of nightly sleep for a week causes impairment similar to those seen after 24 hours of wakefulness. After two weeks of such deficit, the lapses in performance are similar to those seen after 48 hours of wakefulness[22]The number of shifts worked in a month by EMS providers was positively correlated with frequency of reported errors and adverse events [21].In recent years, the International Classification of Sleep Disorders has Officially defined the Shift Work Sleep Disorder(307.45-1) as one that consists of symptoms of insomnia or excessive sleepiness that occur as transient phenomena in relation to work schedules[23].

Workplace safety and errors: Shift work has been shown to negatively affect workers, and has been classified as a specific disorder (shift work sleep disorder). Circadian disruption bt working at night causes symptoms like excessive sleepiness at work and disturbances. Shift work sleep disorder also creates a greater risk for human error at work [3].Shift work disrupts cognitive ability and flexibility and impairs attention, motivation, decision making, speech, vigilance, and overall performance[4].Some studies that estimated the relative risk of incidents in the morning, afternoon, and night shifts of 8 hours shift system, in comparable working conditions, shown an increased risk of $18 \%$ in the afternoon shift, and $30 \%$ in the night shift, as compared to morning shift.More over other studies reported that risk increases over successive shifts by $6 \%$ in the second night, $17 \%$ in the thirdnight, and36\% in the fourth night[24].Also the length of hours at work is a key for fatigue related disorders, as reported by three studies which examined trends in national accident statistics. An aggregated analysis of several studies carried out in English industries[25] showed an almost exponential increase of accidents after eight hour of work; this has also been evidenced in Sweden[26], based on examination of the national database of work accidents, and in Germany through the insurance registries on industrial accidents[27].According to these studies, it is possible to estimate double the risk of accidents when working in a 12 hour shift as compared with an 8 hour shift, as recent survey of more than 75,000 US workers over a $4-$ year period, confirmed a higher risk of injury strictly related to a progressive increase of working hours and reduction of sleep duration[28].

In order to mitigate the negative effects of shift work on safety and health, many countries gave enacted regulations on shift work. The European Union in its directive 2003/88/EC, has established a 48- hour limit on working time(including overtime)per week; a minimum rest period of 11 consecutive hours per 24hour period, and minimum uninterrupted rest period of 24 hours of mandated rest per week[which is an addition to the11 hours of daily rest)[24].The EU directive also limits night work involving "special hazards or heavy physical or mental strain" to an average of eight hours in any 24-hour period[29].The EU directive allows for limited derogation from the regulation, and special provisions allow longer working hours for transportation and offshore workers, fishing vessel workers, and doctors in training [29].Fatigue due to shift work has contributed to several industrial disasters, including the Three Mile Island accident, Space Shuttle Challenger disaster and the Chernobyl disaster[4].The Alaska Oil Spill Commission's final report on the Exxon Valdez oil spill disaster found that it was "conceivable" that excessive work hours contributed to crew fatigue, which in turn contributed to the vessel running aground[30]

Shift work and mortality: A Danish cohort study of 5249 reported general mortality in 1123 shift worker and 4084 day workers, who were followed for 22 years. The relative death risk was 1.1(95\% confidence interval $(95 \% \mathrm{CI})=0.9-1,3)$ for shift workers after adjustment for age and social class[31,AK,4].A British study 
followed 8603 male manual workers from 1956 to 1968[32].In total,1578 deaths were notified The observed and expected number of deaths in day workers were 736 and 756.4,respectively.The corresponding figures for shift workers were 722 and 711.4,and for ex-shift workers 120 and100.9.The authors concluded that shift work would appear to have no adverse effect upon mortality[32].

\section{Adverse health effects}

World Health Organization (WHO) definition of "health", shift work is a risky condition at all the three reference levels, as it is not only a risk factor for many health disorders, but also perturbs psycho-physical homeostasis, and hamper family and social life [33].Frequent adverse health effects among the shift workers includes: cardiovascular disease,gastrointestinal disease, reproductive health ,mental health, and cancer.Cardiovascular disease (CVD): A review of cardiovascular disease in shift workers concluded that there is a $40 \%$ increase in risk. Some studies have indicated increases in cholesterol and hypertension in shift workers. Other research has focused on behavioral factors such as diet,tobacco use, and lack of exercise as likelycause. Some of these studies show an increase mortality among shift workers [34].During the last 15 years, evidence has accumulated indicating that conditions in the work environment contribute to the etiology of CVD.Among the work related risk factors are chemical compounds, noise and vibration. In addition, a number of psychosocial factors, e.g. organization of work, work schedules and behavior, are associated with an increased risk of CVD[35].

Alfredsson et al carried out a study of 334 cases with myocardial infarction and 882 controls, which were selected randomly from general population in the same region. The shift-work exposure was assessed from occupational code, and from an interview of 14,500 people belonging to a random sample of households in Sweden. The results showed that shift work was associated with myocardial infarction (age-standardized relative $\operatorname{risk}(\mathrm{RR})=1.25,95 \% \mathrm{CI}=0.97-62)$ [36]. American study of 79,000 nurses followed for 4 years. The study showed a dose response relationship between years of shift work and coronary heart disease. The results were controlled for cofounders, e.g. smoking, BMIhypertension, diabetes, hypercholestrolaemia,alcohol intake and physical activity [37].In a Danish study, the relative risk of being admitted to hospital due to ischemic heart disease was measured in a cohort of 1293888 men[38].Information on occupation was used to classify each subject into different shift work exposure categories. The results showed that, compared with occupational groups having day work only, men in occupations with frequent night and early morning work had an excess standardized hospitalization ratio of 193, occupational groups with late evening work had an excess risk of 216 , and groups working in rosters covering $24 \mathrm{~h}$ services had an excess risk of 174 [38].

However, it is not always easy to establish a casual relation between shift work and CVD due to many selection biases besides the well-knowncofounders [39].This is the case of ageing for example, which is itself a risk factor for CVD, but when combined with shift work, can be underestimated in elderly shift workers due to "sick shift worker effect", that is workers no longer working on shifts due to intervening health disorders that are more likely to occur with ageing. This was evidenced in a 13-year follow up study on Finish workers, where relative risk of ischemic heart disease was higher after 5 years than after 13 years $(1.59$ vs 1.340 of shift work[40].Also ,the periodical health surveillance, to which shift workers may be subjected more frequently than day workers, could weaken such associations, as shown by Frost et al, in their review of 16 studies concerning CHD and shift work[41].

Gastrointestinal disease (GID):GID comes second to sleep problems are most frequently complained about by shift workers(20-75\% vs $10-25 \%$ of day workers), due to the troubles being connected with phase displacements between mealtimes and normal circadian phases of gastrointestinal functions(e.g. gastric, bile and pancreatic secretions, enzyme activity, intestinal motility, rate of absorption of nutrients, and hunger and satiety hormones), and to changes in food quality and composition(i.e. more pre-packed food and "pep" and soft drinks[42].Many surveys document that gastrointestinal troubles and diseases are more common in shift workers than day workers[39].A recent Japanese study on peptic ulcers, covering about 12000 workers from several sectors, that combined X-rays and endoscopy showed a double in the relative risk of peptic ulcers in shift workers than in day workers $(2.38 \%$ vs $1.03 \%$ for gastric ulcer and $1.37 \%$ vs 0,69 for duodenal ulcer)[43].Moreover, some studies found that infection by Helicobacter pylori is more prevalent in shift workers than day workers, which probably is sign that shift work hampers the natural gastric defence [44]

A very recent systematic review of twenty peer reviewed epidemiological studies, reporting an association between shift work and gastrointestinal diseases, pointed out that four out of six studies showed a statistically significant association with digestive symptoms, five out of six with peptic ulcers, and two of three with functional GI disorders[45].

Psychiatric problems: The mental health effects of stress on a continuum ranging from mild subjective symptoms to overt psychiatric disease include anxiety,tension; anger, depression decreased concentration and other psychiatric disorders[46], Shift workers often complain about irritability, nervousness, and anxiety in relation to more stressful working conditions and higher difficulties in family and social life. 
Persistent disruption of circadianrhythms and sleep deficit may lead to chronic fatigue, mood disorders,neuroticism, as well as to chronic anxiety/ or depression, creating a situation where workers have higher absenteeism and often require administration of psychotropic drugs(sedative and hypnotics)[47],

Diabetes mellitus(DM): Koller et al investigated 300 workers at an Austrian oil refinery and found that the prevalence of endocrine and metabolic disease was $3.5 \%$ in shift workers, $1,5 \%$ in day workers and $2,8 \%$ among drop outs[48].A Japanese study ound a prevalence of $2.1 \%$ in subjects who worked all three shifts,compared with $0.9 \%$ in day workers[49]Kawachi et al conducted a prospective study shift work and risk of coronary heart disease in female nurses, The age-standardized prevalence of diabetes was found to increase with increasing exposure to shift work:never,3,5\%; $1-2$ years,3,2\%;3-5 years,3,5\%;6-9 years,4,4\%;10-14 years,5.0\%;> 15 years 5,6\%[37],A recent study by Nagaya et al examined the relationship between shift workers of insulin resistance, They found that all markers of insulin resistance were more common in shift workers than day workers in the age group $<50$ years[50].

Reproductive Health: A Swedish study showed an association between shift work and low birth weight.[51].That study also reported increased risk of miscarriage in women who worked irregular hours or rotating shifts compared with day workers $(\mathrm{RR}=1.4,95 \% \mathrm{CI}=0.83-2.51) \mathrm{A}$ Chinese study reported that the $0 \mathrm{R}$ of shift work was $2.0(95 \% \mathrm{CI}=1,1=4.1)$ for low birth weight. The estimated effect of rotating shift work on birth weight was- 79 g.[52]..The relationship between work conditions and pregnancy outcome has been reported in three studies based on the Montreal survey of-22 700 single live births. The results showed association between shift work and low birth weight[51].In the service sector ,MacDonald et al[53] also found a significant relationship between shift work and preterm birth. Based on the same data set,one paper reported fetal death in relation to work in pregnancy. They found and increased of spontaneous abortion among shift workers $(R R=1.25)$ [53].Uehata and Sasakawa in a study of 2264 women and found that irregular menstruation and abortions were more common $\mathrm{n}$ shift workers[54].Memelle et al found that shift work was associated with an increased risk of premature births[55].In summary, there is rather strong evidence in support of an association between shift work and pregnancy outcome in term of miscarriage, low birth weight and preterm birth.[ 56 ].

Malignancy:The mortality study by Taylor and Pocock reported a significantly increased incidence of neoplasma in shift workers compared with the general population(SMR=116)[32].In 2007,the International Agency on Research on Cancer(IARC) classified "shift work that involves circadian disruption" as probably carcinogenic to humans"(Group 2A) on the basis of "limited evidence in humans for carcinogenicity of shiftwork that involve night work", and sufficient evidence in experimental animals for carcinogenicity of light during the daily dark period(biological night)",This was referring breast cancer in women in particular, on which 9 studies have been published so fa 6 of which were positive, but there are some other sporadic indications for cancer of the endometrium(1 positive study),prostate, 3 studies 2 positive),colon-rectal( 3 studies 1 positive), and non-Hodgkin lymphoma(1 positive study)[57,58,61].

A recent Danish case control study reported an increased risk of breast cancer among 30 to 54 year- old women who worked predominantly $(\mathrm{OR}=1,5,95 \% \mathrm{CI}=1.3-1.7)[59]$. The results were adjusted for age, socialclass, age at birth of first child, age at birth of last child and number of children. Epidemiological studies of women with various kinds of shift work have demonstrated an elevated risk of breast cancer; occupation groups include flight attendants, nurses, and telegraph operators. However, other carcinogenic exposures could have been responsible for increased risk in specific occupations,e.g,ionizing radiation in airline cabin attendants [59].There has been discussion on whether low levels of the hormone melatonin might increase the risk of specific cancers[60], This hypothesis has been supported by the studies showing decreased risk of cancer in blind people.

The mechanisms by which circadian disruption may favour the induction and/or promotion of malignant tumors are complex and multifactorial. The multi-level endocrine changes caused by circadian disruption with melatonin suppression via light at night lead to the oncogenic targeting of endocrine responsive breast in women and possibly the prostate in men.Sleep deprivation leads to the suppression of immune surveillance which may permit the establishment and/ or growth of malignant tumors [33]. However, there is no conclusive evidence that might work per se increases the risk of cancer[56].

\section{Management}

Though shift work itself remains necessary in many occupations, employers can alleviate some of the negative health consequences of shift work. The United States National Institute for Occupational Safety and Health recommends employers avoid quick shift changes and rotating shift schedules should rotate forward. Employers should also attempt to minimize the number of consecutive night shifts, long work shifts and overtime work. A poor work environment can exacerbate the strain of shift work. Adequate lighting, clean air, proper heat and air conditioning, and reduced noise can all make shift work more bearable for workers [15]. Shift work schedule: Algorithmic scheduling of shift work can lead to what has been colloquially termed as 
"clopening" where the shift -work has to work the closing shift of one day and the opening shift of the next day back-to-back resulting in short rest periods between shifts fatigue[61].Co-opting employees to fill the shift roster helps toensure that human costs[62] are taken into account in way which is hard for and algorithm to do as it would involve knowing the constraints and considerations of each individual shift worker and assigning a cost metric to each of those factors[63].Shift based hiring which is a recruitment concept that hires people for individual shifts, rather than hiring employees before scheduling them into shifts enables workers to indicate their preferences and availabilities for unfilled shifts through a shift binding mechanism. Through this process, the shift hours are evened out by human- driven market mechanism rather than algorithm process [64].

Therapy:Melatonin may increase sleep length during both daytime and night-time sleep in people wo work at night shifts.Zopiclone has also been investigated as a potential treatment, but it is unclear if it is effective in increasing daytime sleep in shift workers. There are no reports of side effects[3].Modafinil and RModanifil are useful to improve alertness and reduce sleepiness in shift workers[3].Modanifil has a low risk of abuse compared to other similar agents[65].In post-marketing surveillance Modanifil was associated with severe Steven Johnson syndrome. The European Medicines Agency withdrew the license for Modanifil for shift workers for the European market because it judged that the benefits did not outweigh the side effects [3]..Using caffeine and naps before night shifts can decrease sleepiness.Caffeine also shown to reduce errors made by shift workers [3].

\section{Preventive measures}

The practices and policies put in place by managers of round-the-clock 0r 24/7 operations can significantly influence shift worker alertness (hence safety) and performance [14].Air traffic controllers typically work an 8-hour day,5 days a week. Research has shown that when controllers remain "in position" for more than two hours,even at low traffic levels,performance can deteriorate rapidly, so they are typically place "in position" for 30 minutes interval(with 30 minutes between intervals)[66].Mandating a minimum of 10 hours between shifts is an effective strategy to encourage adequate sleep for workers.Allowing frequent breaks and scheduling 8-10 hour shifts instead of 12 hour shifts can also minimize fatigue and help to mitigate the negative health effects of shift work[7].

A 42 hours work week allows for the most even distribution of work time.A 3:1 ratio of work days to days off is most effective for eight hour shifts,and 2:2 ratio of work days to days off is most effective for twelve hours shifts[14].Twelve- hour shifts are also used with a very slow rotation in the petroleum industry. Twelvehour shifts are common in health care and emergency services [13].Rotations of shifts can be fast, in which a worker changes shifts more than once a week, orslow, in which a worker changes shifts less than once a week. Rotations can be forward, when a subsequent shift start later, orbackward, when a subsequent shift starts earlier[13].

\section{Conclusions}

Shift work increases the risk for many health disorders that include cardiovascular disease,diabetes, risk of developing breast cancer, reproductive health, and metabolic disorders. Prevention includes good shift work schedule and better management.

\section{References}

[1]. Sloan Work \& Family Research, Boston College. Shift Work,Definition(s) of.Retrieved 2014-09-25.

[2]. Alterman T,Luckhaupt SE,Dahlhamer JM,et al.Prevalence rates of work organization characteristics among workers in the U.S.Datafrom the 2010 National Health Services Survey.Am J Ind Med.2013;56(6):647-59

[3]. Liira J,Verbeek JH,Costa G,et al.Pharmacological interventions for sleepiness and sleep disturbances caused by shift work. The Cochrane database of systematic reviews.2014;8:CD009776.

[4]. Ker Katherine,Edwards Philip James,Felix LM,et al.Caffeine for prevention of injuries and errors in shift workers. The Cochrane Database of Systematic Reviews for the prevention of injuries in shift workers. The Cochrane Database of Systematic Reviews.2010;(5):CD008508.

[5]. Centers for Disease Conrol and Prevention.Short sleep duration among workers-United States,2010.MMWR 2012;61(16):28185.PMID 22534760.

[6]. Yong Gan.Shift work and Diabetes mellititus:a meta-analysis of observational studies.Occup Environ Med.2014;72((Online First):72-78.

[7]. Caruso Claire C(2012).Running Empty:Fatigue and Healthcare Professionals. NIOSH .Workplace Safety and Health.Medspace and NIOSH.

[8]. Megdal SP,Kroenke CH,Laden F,et al.Night work and breast cancer risk:A systematic review and meta-analysis.Eur J Cancer.2005;41(13):2023-32.

[9]. IARC Press Release No.180(http://www.iare.fr/ENG/Press Release/pr180a.html)

[10]. Beck E,Sieber WJ,Tejo R.Management of cluster headache. Am Family Physic.2005;71(4):717-24

[11]. Vyas MV,Garg AX,Iansavichus AV,et al.Shift work and vascular events:systematic review and meta-analysis.Br Med J(Clinical Research Edition).2012;345:e4800

[12]. Fido A,Ghali A.Deterimental effects of variable work shifts on quality of sleep,general health and work performance.Med Princ Pract(Abstract)2008;17(6):453-7. 
[13]. Erren Thomas C,Herbst C,Koch Melissa S,et al.(20130).Person-directed non-pharmacological interventions for preventing and treating sleepiness and sleep disturbances caused by shift work. The Cochrane Library.

[14]. Miller JC(2013).Fundamentals of Shiftwork Scheduling, $3^{\text {rd }}$ Edition.Fixing Stupid. Smashwords.

[15]. Rogger R,Rosa Mochael J Colligan(1997).Plain Language About Shiftwork (PDF). Cincinnati,Ohio:National Institute for Occupational Safety and Health.

[16]. Santhi N,AEschbach D,Horowitz TS,et al.The impact of sleep timing and bright light exposure on attentional impairment during night work..J Biol Rhythms.228;23(4):341-52.

[17]. BargerLaura,Lockely SW,Rajaratnam SMW,et al.Neurobehavioral Health and safety Consequences Associated WITH Shift Work in Safety -SensitiveProfessions. Current Neurology and Neuroscience Reports.2009;9(2):9:155-164.

[18]. Folkard S,Do permanent night workers show circardian adjustment.A review based on the endogenous melatonin rhythm.Chronobiol Int.2008;25:215-24.

[19]. Akerstedt T.Shift work and disturbed sleep/wakefulness.Occup Med(Lond). 2003;53:89-94.

[20]. Mollicone DJ,Van Dongen HPA,Dinges DF.Optomizing sleep/ wake schedules in space:Sleep during chronic nocturnal sleep restriction with and without diurnal naps.ACTANAUTICA 60(4-7):354-361.Doi:10.1016/j.actaastro.2006.09.022.

[21]. Patterson PD,Weaver MD,Frank RC,et al.Association Between Poor Sleep. Fatigue, and Safety Outcomes in Emergency Medical Services Providers.Prehospital Emergency Care.2012;16:86-97.

[22]. Van Dongen HP,Maislin G,Mullington JM,et al.The cumulative cost of additional wakefulness: dose-response effects on neurobehavioral functions and sleep psychology from chronic sleep restriction and total sleep deprivation. Sleep. 2003;(26):117-26.

[23]. ASSM.ICSD 2005.International classification of sleep disorder, revised diagnostic and coding.Darien,IL:American Academy of Sleep Medicine.2005.298 p.

[24]. Folkard S,Tucker P.Shift work,safety and productivity.Occup Med(Lond) 2003;53:95-101

[25]. Folkard S.Effects on performance efficiency.In:Colquhoun WP,Costa G,Folkard S,Kanauth P,editors.Shiftwork:problems and solutions.Frankfurt M:Peter Lang 1996.p.65-87.

[26]. Akerstedt T.Work injuries and time of day-national data.Shift Int News 1995;12:2.

[27]. Hanecke K,Tiedemann S,Nach reiner F,et al.Accifent risk as a function of hour at work and time of the day as determined from accident data and exposure models for the German working population.Scand J Work Environ Health.1998;24:43-8.

[28]. Lombardi DA,Folkard S,Willetts JL,et al.Daily sleep,weekly working hours, and risk of work-related injury:US National Health Interview Survey(2004-2008).Chronibiol Int 2010;27:1013-30.

[29]. Directive 2003/88/EC of the European Parliament and of the Council of 4 November 2003 concerning certain aspects of the organization of working time(http://eur-lex.europa-lex.eu/legal-content/EN/TXT/?qid=14328263433368\&uri=URISERV:C10418)

[30]. Final Report:Spill-The Wreck of the Exxon Valdez:Implications for safety Transportation of Oil(http://docs.lib.noaa.gov/noaa.documents/NOAA related docs_spills/spill_wreck_ExxonValdez_1990.pdf).Alaska 0il Spill Commission (February 1990).

[31]. Boggild H,Saudicani P,Hein HO,et al.Shift work,social class,and ischemic heart disease in middle age and elderly men;a 22 year follow up in the Copenhagen male Study.Occup Environ Med.1999;56:640-45.

[32]. Taylor PJ,Pocock SJ.Mortality of shift and day worekers.1956-1968.Br J Ind Med.192;29:201-207.

[33]. Costa G.Shift Work and Health:Current Problems and Preventive Actions. Safety Health Work.2010;1:112023.

[34]. Knutsson A,Boggild H.Shift work and cardiovascular disease. Review of disease mechanisms(review).Rev Environ Health.2000; 15:359[PMID:11199246].

[35]. Boggild H,Knutsson A.Shift work,risk factors and cardiovascular disease.Scand J Work Environ Health. 1999;25:85-99.

[36]. Alffredsoon L,Karasek RA,Theorell T.Myocardial infarction risk and psychosocial environment.Analysis of the male Swedish working force.Soc Sci Med.1982;16:463-67.

[37]. KawachiJ,Colditz GA,Stamfer MJ,et al.Prospective study of shift work and risk of coronary heart disease in women.Circulation.1996;92:3178-82

[38]. Tuchsen F,Working hours and ischemic heart disease in Danish Men:a 4 -year cohort study of hospitalization.Int $\mathrm{J}$ Epidemiol.1993;22:215-21.

[39]. Knutsson A,Health disorders of shift workers.Occup Med (London)2003;53:103-8.

[40]. Virkunen H,Harma M,Kauppinen T,et al.The triad of shift work,occupational noise, and physical work load and risk of coronary heart disease. Occupy Environ Med.2006;63:378-86.

[41]. Frost P,Kolstad HA,Bonde JP.Shift work and the risk of ischemic heart disease-a systematic review of epidemiologic evidence. Scand J Work Environ Health. 2009; 35:163-79.

[42]. Lennernas M,Hambraeus L,Akerstedt T.Nutrient intake in day and shift workers. Work \& stress.1994;8:332-42.

[43]. Segawa K,Nakazawa S,Tsukamoto Y et al.Peptic ulcer is prevalent among shift workers.Dig Dis Sci.1987;32:440-53

[44]. Zober A,Schilling D,Ott MG,et al.Helicobacter pylori infection:prevalence and clinical relevance in a large company.J Occup Environ Med.1998;40:586-94.

[45]. Knutsson A,Boggild H.Gastrointestinal disorders among shift worker.Scand J Work Environ.2010;36:85-95

[46]. Seward PJ.Occupational Stress.In:Current Occupational \& Environmental Medicine. $3^{\text {rd }}$ ed.Joseph LaDou(edit).McGraw Hill,2004.pp.603-618.

[47]. Cole RJ,Loving RT,Kripke DF.Psychiatric aspects of shift work.Occup Medicine. 1990;5:301-14.

[48]. Koller M,Kundi M,Cervinka R.Field studies of shift at an Austrian oil refinery.J Health Psychilogical Wellbeings of workers who drop out of shift work. Ergonomics. 1978;21:835-47.

[49]. Mikuni E,Ohoshi T,Hayashi K,et al.Glucose intolerance in an employed population. Tohoku J Exp Me.1983;141:251-56.

[50]. Nagaya T,Yoshida H,Takahashi H,et al.Markers of insulin resistance in day and shift workers aged 30-59 years. In Arch Occup Environ Health.2002;75:562-68.

[51]. Axelsson G,Rylander R,Molin I.Outcome of pregnancy in relation to irregular and inconvenient work schedule.Br $\mathbf{J}$ Ind Med.1989;46;393-98.

[52]. Xu X,Ding M,Li B,et al.Association of rotating shiftwork with preterm births and low birth weight among never smoking women testile workers in China.Occup Environ Med.1994;51:470-74.

[53]. MacDonald AD,MacDonald JC,Armstrong $\mathrm{B}$,et al.Prematurity and and work in birth weight for gestational age.Br $\mathrm{J}$ Ind Med.1989;46:196-99.

[54]. Uehata T,Sasakawa N.The fatigue and maternity disturbances of night workwomen.J Hum Ergol.1982;11(Suppl,):465-74.

[55]. Mamelle N,Laumon R,Lazar P.Prematurity and occupational activity during pregnancy.Am J Epidemiol.1984;119:309-22.

[56]. Kenutsson A.Health disorders of shift Workers.Occup Med.2003;53:103-8.

[57]. Straif K,Baan R,Grosse Y,et al.Carcinogenicity of shift-work,painting and firefighting. Lancet 0ncol.2007;8:1065-6. 
[58]. Kolstad HA,Nightshift work and risk of risk of breasy cancer and other cancers-a critical review of the epidemiologic evidence.Scand Work Environ Health.2008;34:5-22.

[59]. Hansen J,Increased Brest cancer risk among women who work predominantly at night.Epidemiol.2001;12:74-77.

[60]. Cos S.Sanchez-Barcelo EJ.Melatonin and mammary pathological growth.Front Neuroendocrinol.200;21:133-70.

[61]. The "Clopening" Shift May Soon Be a Thing of the Past.Boston Com.Retrieved 3 February 2016.

[62]. http://www.workplacestratehiesformentalhealth.com

[63]. http://ewh.ieee.org/conf/http/presentations/27.pdf

[64]. "In Service Sector,No Rest for the Working". The New York Times.22 February 2015.Retrieved 3 February 2016.

[65]. Wisor J..Modanfinil as a catecholaminergic agen empirical evidence and unanswered questions.Frontiers in Neurology.2013;4:139

[66]. Inc.,Intrigma.Five Foundations For A Fair PhysicianSchedule. Retrieved 2016-0718. 